\title{
Treatment Impacts on Temporal Microbial Community Dynamics During Phytostabilization of Acid-generating Mine Tailings in Semiarid Regions
}

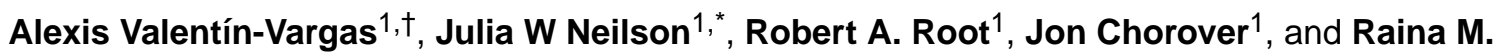 \\ Maier $^{1}$ \\ ${ }^{1}$ Department of Soil, Water and Environmental Science. 429 Shantz Bldg. \#38, 1177 E. Fourth \\ Street, University of Arizona, Tucson, Arizona 85721-0038, USA
}

\section{Abstract}

Direct revegetation, or phytostabilization, is a containment strategy for contaminant metals associated with mine tailings in semiarid regions. The weathering of sulfide ore-derived tailings frequently drives acidification that inhibits plant establishment resulting in materials prone to wind and water dispersal. The specific objective of this study was to associate pyritic mine waste acidification, characterized through pore-water chemistry analysis, with dynamic changes in microbial community diversity and phylogenetic composition, and to evaluate the influence of different treatment strategies on the control of acidification dynamics. Samples were collected from a highly instrumented one-year mesocosm study that included the following treatments: 1) unamended tailings control; 2) tailings amended with $15 \%$ compost; and 3) the $15 \%$ compostamended tailings planted with Atriplex lentiformis. Tailings samples were collected at 0, 3, 6 and 12 months and pore water chemistry was monitored as an indicator of acidification and weathering processes. Results confirmed that the acidification process for pyritic mine tailings is associated with a temporal progression of bacterial and archaeal phylotypes from $\mathrm{pH}$ sensitive Thiobacillus and Thiomonas to communities dominated by Leptospirillum and Ferroplasma. Pore-water chemistry indicated that weathering rates were highest when Leptospirillum was most abundant. The planted treatment was most successful in disrupting the successional evolution of the Fe/Soxidizing community. Plant establishment stimulated growth of plant-growth-promoting heterotrophic phylotypes and controlled the proliferation of lithoautotrophic Fe/S-oxidizers. The results suggest the potential for eco-engineering a microbial inoculum to stimulate plant establishment and inhibit proliferation of the most efficient Fe/S-oxidizing phylotypes.

\section{Graphical abstract}

\footnotetext{
*Corresponding author. jneilson@email.arizona.edu; Tel: +1-520-621-9759; Fax: +1-520-626-6782; Department of Soil, Water and Environmental Science, 1177 E. Fourth Street, Shantz Bldg. Room 429, University of Arizona, Tucson, Arizona 85721-0038, USA.

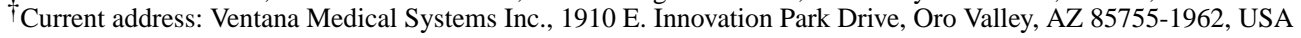

Conflict of Interest

The authors declare no conflict of interest.

Publisher's Disclaimer: This is a PDF file of an unedited manuscript that has been accepted for publication. As a service to our customers we are providing this early version of the manuscript. The manuscript will undergo copyediting, typesetting, and review of the resulting proof before it is published in its final citable form. Please note that during the production process errors may be discovered which could affect the content, and all legal disclaimers that apply to the journal pertain.
} 


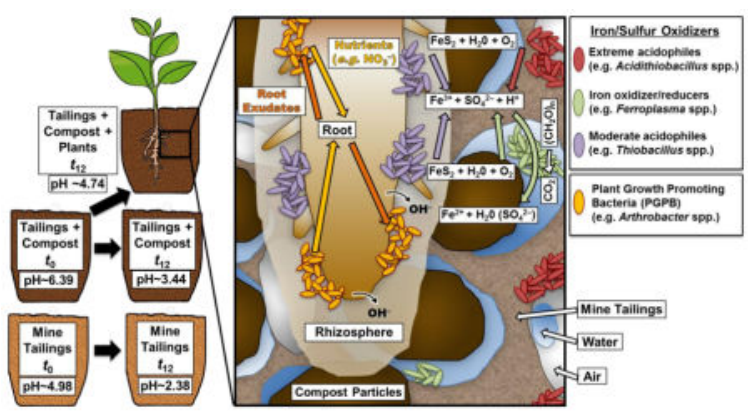

\section{Keywords}

Iron oxidation; sulfur oxidation; mine reclamation; plant growth promoting bacteria; microbial diversity

\section{Introduction}

Hardrock mining is a major source of environmental contamination in global arid and semiarid regions (e.g. western North and South America, southwestern Europe, central Asia, South Africa, central Australia) where tailings, that are the residuals left after grinding and extraction of the ore, are a prominent legacy of mining activity. Surface layers of mine waste at many legacy sites contain weathered and oxidized sulfide-rich tailings characterized by elevated quantities of metal(loid)s. Further, oxidative weathering of tailings originating from sulfide-rich deposits frequently results in highly acidic conditions in the absence of significant carbonate neutralization potential. In contrast, tailings that remain neutral after extended weathering typically originated with low pyrite concentrations or high carbonate neutralizing potential (Dold and Fontboté, 2001). For sulfide-rich ore tailings, conditions created by acidification, combined with poor nutrient availability and poor water-holding capacity, severely limit natural plant colonization making the tailings highly prone to eolian dispersion and water erosion (Mendez and Maier, 2008, Zornoza et al., 2017). These conditions exacerbate the potential for these sites to negatively impact neighboring communities and ecosystems.

Direct planting or phytostabilization is a reclamation technology designed to facilitate in situ containment of dust and metal contaminants and initiate ecosystem regeneration (Gil-Loaiza et al., 2016; Valentín-Vargas et al., 2014; Zornoza et al., 2017). Current research suggests that development of the nutrient cycling and plant growth promoting capacity of the diversity-poor, below-ground microbial communities of mine waste is critical to revegetation success (Li et al., 2016a; Li et al., 2015; Mendez et al., 2008; Mendez et al., 2007; SolísDomingez et al., 2012). However, strategies designed to engineer this process remain poorly understood despite the consensus that improved knowledge of the microbial ecology of mine waste is essential to sustainable plant establishment (Garris et al., 2016). Here we investigate the temporal microbial community dynamics associated with compost-assisted phytostabilization of sulfidic mine tailings with high acid-generating potential. 
Freshly deposited sulfidic tailings are typically neutral to alkaline, however in situ weathering in semiarid regions of pyrite $\left(\mathrm{FeS}_{2}\right)$ and other iron-sulfide minerals in the tailings (Schippers et al., 2010) generally results in highly acidic conditions in near surface layers due to $\mathrm{O}_{2(\mathrm{~g})}$ saturated water through-flux and episodic wetting and drying cycles (Hayes et al., 2009; Hayes et al., 2014). Near complete sulfide-species depletion to depths of $50 \mathrm{~cm}$ has been observed on legacy sites over time frames shorter than 50 years (Hayes et al., 2009; Hayes et al., 2014), resulting in $\mathrm{pH}$ values ranging from 2.3 to 5.4. Research has shown that plant growth is inhibited at these acidic $\mathrm{pH}$ levels unless amendments are added that help buffer the pH (Mendez et al., 2007; Solis-Dominguez et al., 2012; Shu et al., 2005; GilLoaiza et al., 2016). As abiotic $\mathrm{FeS}_{2}$ oxidation drives the $\mathrm{pH}$ below 5, tailings oxidation becomes increasingly dominated by microbially mediated catalysis, which accelerates acidification. The model for $\mathrm{FeS}_{2}$ oxidation shows that the main precursor of acid in pyritic mine tailings is, indeed, a microbially catalyzed secondary oxidation reaction where ferric iron, rather than oxygen, serves as main oxidant (Nordstrom and Southam, 1997; Ma and Lin, 2013). This reaction is favored at $\mathrm{pH}$ values below 4 , where ferric iron becomes soluble and, therefore, bioavailable for microorganisms to employ as an oxidant (Kirby and Brady, 1998; Johnson and Hallberg, 2005; Akcil and Koldas, 2006; Ziegler et al., 2013).

Studies focused on understanding the microbial dynamics of pyritic mine-tailing oxidation have observed correlations between microbial community structure, substrate $\mathrm{pH}$ and the mineralogy of the tailings (Chen et al., 2014; Chen et al., 2013; Korehi et al., 2014; Li et al., 2016a; Liu et al., 2014; Mendez et al., 2008). Highly acidic tailings (pH 2.5-3.6) support communities dominated by autotrophic Fe- and S-oxidizing populations several orders of magnitude more abundant than co-occurring heterotrophic populations, whereas less acidic tailings ( $\mathrm{pH}$ 5.7-6.5) located at the same site harbor communities with more abundant and diverse heterotrophic populations (Korehi et al., 2014; Mendez et al., 2008; Solís-

Dominguez et al., 2012). Several studies observed distinct microbial communities associated with pyritic tailings of different $\mathrm{pH}$ levels and variable oxidation states. It was hypothesized that the oxidation process is driven by distinct microbial assemblages at different stages of acidification (Chen et al., 2014; Chen et al., 2013; Korehi et al. 2014). In addition, phytostabilization greenhouse- and field-scale studies in highly acidic tailings have observed that plant establishment is associated with quantitative increases in neutrophilic heterotrophic populations and concurrent decreases in Fe/S oxidizing microbial taxa (GilLoaiza et al., 2016, Li et al., 2016a; Mendez et al., 2007; Solís-Dominguez et al., 2012).

Here we report on a highly instrumented, long-term greenhouse experiment conducted to track the biogeochemical weathering processes associated with the acidification of pyritic mine tailings and to evaluate the impact of different reclamation treatments on those dynamics. Oxidized and unoxidized pyritic tailings collected from the Iron King Mine and Humboldt Smelter Superfund (IKMHSS) site (NPL, 2008) in Dewey-Humboldt, AZ, USA (Valentin-Vargas et al., 2014; Nelson et al. 2015) were combined in a ratio (3:1) designed to simulate the surface conditions (top $40 \mathrm{~cm}$ ) of a parallel field study at the IKMHSS site (GilLoaiza et al., 2016). Treatments included an unamended control, tailings amended with $15 \%$ compost, and the 15\%-compost-amended tailings planted with Atriplex lentiformis (quailbush). Previously published results from this study (Valentin-Vargas et al., 2014) used denaturing gradient gel electrophoresis (DGGE) to profile 16S rRNA bacterial and archaeal 
genes and documented treatment-specific, dynamic changes in microbial community structure during the 12 month experiment. CCA analysis revealed that the most significant environmental variables influencing microbial community structure were $\mathrm{pH}$ and compost for bacteria, and $\mathrm{pH}$ and electrical conductivity (EC) for archaea. The specific objective of the present study was to employ high throughput DNA sequencing of 16S rRNA gene amplicons combined with pore water chemistry analysis to: (i) define transitions in diversity and phylogenetic composition of the bacterial and archaeal communities that explain the previously published temporal changes in community structure, (ii) characterize the effect of reclamation treatment and pore-water chemistry on the temporal dynamics of Fe/S-oxidizing microbial communities during the biogeochemical weathering of pyritic tailings, and (iii) advance our understanding of microbial treatments that could be developed to eco-engineer controls on the in situ pyrite oxidation processes. This study is the first temporal evaluation of the capacity of specific reclamation treatments to control microbial community dynamics during oxidation of pyritic mine tailings.

\section{Materials and Methods}

\subsection{Collection of mine tailings and design of greenhouse, mesocosm experiment}

The source of the mine tailings used for the greenhouse experiment was the IKMHSS tailings pile; part of a highly-contaminated former mine site (NPL, 2008) located in the high desert of Northern Arizona, USA in the town of Dewey-Humboldt $\left(34^{\circ} 30^{\prime} 02.11^{\prime \prime} \mathrm{N}, 112^{\circ}\right.$ $15^{\prime} 08.75^{\prime \prime} \mathrm{W}$ ) (Hayes et al., 2014; Root et al., 2015). The IKMHSS tailings pile has an oxidized surface layer (0-20 cm depth) rich in sulfate minerals (e.g. jarosite, gypsum), overlying the unoxidized subsurface material (> $35 \mathrm{~cm}$ depth) rich in iron sulfides (e.g. pyrite). For this study, oxidized surface tailings were collected from three locations on the pile. Unoxidized sulfide-stable subsurface tailings were collected from one location on the pile. Tailings from each sampling location were screened to $2 \mathrm{~cm}$ and homogenized on-site. The tailings were transported to a greenhouse facility in Tucson (AZ), where they were mixed in a 3:1 mass ratio of oxidized surface tailings to unoxidized subsurface tailings using a cement mixer. The tailings mixture was designed to create a substrate representative of the variable top $40 \mathrm{~cm}$ of the IKMHSS tailings pile in which some subsurface unoxidized tailings were mixed with oxidized surface tailings during field preparation and plowing for the parallel field study. Homogenized tailings were sieved to $\leq 0.5 \mathrm{~cm}$. A 12 -month mesocosm experiment was set up at the greenhouse in highly instrumented containers $(1 \mathrm{~m}$ in diameter and $50 \mathrm{~cm}$ in depth). Triplicate mesocosms of three treatments were created and arranged in a spatially randomized design: (i) Tailings only (TO-1, TO-2, TO-3); (ii) Tailings mixed with $15 \%$ dry-weight/dry-weight (w/w) compost (TC-1, TC-2, TC-3) to a depth of 20 $\mathrm{cm}$; and (iii) Tailings mixed with $15 \%$ (w/w) compost to a depth of $20 \mathrm{~cm}$ and seeded with Atriplex lentiformis (quailbush) (QB-1, QB-2, QB-3). This native plant species was selected based on criteria described by Solís-Domínguez et al. (2012). All mesocosms were irrigated immediately following seeding and thereafter at an average rate of $1 \mathrm{~cm}$ weekly $(7.5 \mathrm{~L})$. Further details of the mesocosm setup are available in Valentín-Vargas et al. (2014). 


\subsection{Mesocosms sampling and processing}

Core samples ( $2.5 \mathrm{~cm}$ in diameter) through the top $15 \mathrm{~cm}$ of the tailings profile were collected from the mesocosms at: $3\left(t_{3}\right), 6\left(t_{6}\right)$, and $12\left(t_{12}\right)$ months. Time $0\left(t_{0}\right)$ analyses were performed on triplicate $\mathrm{TO}$ and TC grab samples collected immediately following homogenization with the TC $t_{0}$ samples serving as representative starting material for both TC and QB. QB cores were collected by harvesting a single representative plant of average appearance and height from each replicate mesocosm. The shoot was cut at the substrate surface and the core sampler was then centered over the trimmed stalk to maximize the retrieval of rhizosphere-influenced tailings material. All cores were stored on ice and transported to the laboratory where the core material was homogenized in a sterile bag and stored at $-20^{\circ} \mathrm{C}$ until processed for microbial analysis.

Pore water collected from Prenart Superquartz tension samplers located at depths of 5 and $15 \mathrm{~cm}$ was used for chemical and physical analysis. Water samples were filtered $(0.45 \mu \mathrm{m}$, GHP hydrophilic polypropylene) and analyzed for $\mathrm{pH}, \mathrm{EC}$, dissolved organic carbon (DOC), total dissolved nitrogen (TDN), sulfate $\left(\mathrm{SO}_{4}{ }^{2-}\right)$, and dissolved metal(loid)s (i.e. Fe, As) as described previously (Valentín-Vargas et al., 2014). The pore water data reported in this study represents an analysis of the water collected on the day that the soil cores were sampled for $t_{3}, t_{6}$, and $t_{12}$. Pore water samples for $t_{0}$ represent samples collected following the first irrigation immediately after seeding. Water samples collected from $5 \mathrm{~cm}$ and $15 \mathrm{~cm}$ depths were averaged to generate single values from each mesocosm for each time point. Values from mesocosms representing the same treatment were averaged to generate a single value for each time point. The net acid-producing potential (NAPP) for the tailings was determined as described by Solís-Dominguez et al. (2011).

\subsection{DNA extraction and Illumina-based sequencing of 16S rRNA genes}

Community DNA was extracted from $0.5 \mathrm{~g}$ core subsamples using the FastDNA SPIN Kit for Soil (MP Biomedicals, Solon OH, USA) with modifications to the manufacturer's protocol to enhance DNA yield (see Valentín-Vargas et al. [2014] for details). DNA extracts were purified with the Wizard DNA Clean-Up System (Promega, Madison WI, USA) and then quantified using a TBS-380 Fluorometer (Turner BioSystems, Sunnyvale CA, USA) with PicoGreen dye (Invitrogen, Carlsbad CA, USA) according to the manufacturer's directions.

PCR amplification, purification, and sequencing of the V4 region of the 16S rRNA gene were performed using bar-coded primers 515F/806R, targeting bacteria and archaea, following protocols described previously (Caporaso et al., 2011; Caporaso et al., 2012) and adapted for the Illumina MiSeq platform (Illumina, San Diego CA, USA). Detailed protocols and primers sequences are available from the Earth Microbiome Project (www.earthmicrobiome.org). Demultiplexing, quality filtering, and OTU picking of the iTag reads were performed in the Quantitative Insights Into Microbial Ecology (QIIME 1.7) pipeline, using default parameters (Caporaso et al., 2011; Kuczynski et al., 2011). The quality filtering parameters (QIIME 1.7 default) were defined as: (i) 75\%, minimum percentage (of total read length) of consecutive high-quality base calls to retain read; (ii) 3 , maximum number of consecutive low-quality base calls allowed before truncating a read; 
(iii) 0 , maximum number of ambiguous (N) characters allowed in a sequence; and (iv) 3 , last quality score considered low quality (Bokulich et al. 2013). The assignment of sequences into OTUs (97\% identity cut-off value) was based on a closed-reference OTU picking protocol, where the UCLUST algorithm (Edgar, 2010) was applied to search for homologous sequences in a subset of the Greengenes 13_5 database (DeSantis et al., 2006). We acknowledge that some of the novel diversity present in the microbial communities may not have been included due to our decision to use closed-reference OTU-picking, but our priority in this analysis was to focus on the relative abundance of known, well-characterized organisms with predictive functions. Raw sequence data sets are available from NCBI's Sequence Read Archive under accession number: SRP032419.

\subsection{Statistical Analysis}

Samples were collected from replicate mesocosms at each time point and analyzed to identify treatment differences. The taxonomic data was normalized to compensate for variable sequencing depths by means of the Cumulative Sum Scaling method (Paulson et al., 2013) and the normalized data was then subjected to alpha-diversity analysis calculated using Simpson's evenness (1-D) and Shannon-Weiner's $(H)$ indices. Alpha-diversity rarefaction curves were calculated as described by Krebs (1999), with iTag reads normalized to 5,700 sequences. Changes in beta-diversity and their statistical significance were evaluated by Non-Metric Multidimensional Scaling (NMDS) and Analysis of Similarities (ANOSIM), respectively. Both analyses were based on Bray-Curtis distance matrices calculated from relative abundance data of OTUs. Similarity Percentage Analysis (SIMPER) was conducted to determine which OTUs contributed most to the average dissimilarity in microbial community structure between treatments. Only OTUs contributing to the top 50\% of the total average dissimilarity are reported. A Linear Discriminant Analysis (LDA) Effect Size (LEfSe) method (Segata et al., 2011) was used to find statistically significant microbial indicators associated with each treatment. Taxonomic data normalization and the alphadiversity analysis were performed on the MicrobiomeAnalyst web-based tool (Dhariwal et al., 2017). All remaining statistical analyses of sequence and taxonomy data including NMDS, ANOSIM, and SIMPER were conducted with PAST 2.16 (Hammer et al., 2001). The LEfSe was conducted using a Galaxy-based web tool available here: http:// huttenhower.sph.harvard.edu/galaxy/root. Statistical analyses of pore water chemistry was done using the SAS JMP v12. For a comprehensive statistical evaluation of the impact of environmental parameters on microbial community structure, please refer to Valentin-Vargas et al. (2014).

\section{Results}

\subsection{Treatment effects on environmental parameters}

Chemical analysis of the tailings mixture used in the mesocosm experiments revealed that the incorporation of unoxidized tailings effectively increased the NAPP of the tailings from 1.60 moles acid $\mathrm{kg}^{-1}$ (oxidized tailings alone) to 4.67 moles acid kg-1 (3:1 mixture), adding significant acidification potential to the system (Valentín-Vargas et al., 2014). As explained previously (Valentín-Vargas et al., 2014), a rapid decline in $\mathrm{pH}$ was observed in the TO treatment (Table 1) over the first 6 months of the study. The final mineral composition of the 
TO material was similar to that of the surface layers of the IKMHSS site (Hayes et al., 2014) with no evidence for reduction of the oxidized secondary minerals (e.g. jarosite, schwertmannite, ferrihydrite) to sulfides (Root, R.A, personal communication). Amendment with compost increased the tailings $\mathrm{pH}$ at $t_{0}$ by providing a proton-consumption buffering capacity (Table 1), however, the buffering capacity in the TC treatment was exhausted after 6 months at which time a rapid decrease in $\mathrm{pH}$ was observed. In the QB treatment, plants germinated within the first week, were thinned by $50 \%$ following plant establishment, and remained present for the duration of the experiment. Final $\mathrm{pH}$ for the QB treatment was significantly higher $(\mathrm{p}<0.05)$ than for TC, suggesting that quailbush establishment helped mitigate acidification of the tailings in the compost-amended treatments.

Important differences in pore water chemistry were observed as a function of treatment (Table 1). DOC and TDN pore water concentrations were two orders of magnitude higher than those of the TO treatment for much of the experiment. Compost amendment led to elevated EC levels for TC and QB that peaked at $t_{0}$ and then declined. A significant negative correlation was observed across all treatments between pore water $\mathrm{pH}$ and the log of iron $(\mathrm{Fe})$ concentration $(\mathrm{r}=-0.91, \mathrm{p}<0.0001)$ demonstrating a strong association between acidification and the weathering of the pyritic materials. Pore-water Fe concentrations were consistently higher in the TO-treatment than in TC and QB. We attribute this pattern to a control on metal(loid) mobilization by compost and plant establishment, combined with differential progressions in the microbial dynamics of the respective treatments. Pore water Fe concentration for TC and QB did not increase significantly until $t_{12}$ which was concurrent with observed decreases in pore water $\mathrm{pH}$.

\subsection{Treatment effects on microbial community diversity dynamics}

Here we associate successional changes in community diversity and phylogenetic composition with the tailings treatment and fluctuations in pore water chemistry using highthroughput 16S rRNA amplicon analysis. From 301,174 single-end reads, 148,043 ( 49\%) reads remained after quality filtering and picking of operational taxonomic units (OTUs). The acidic, high-metal chemistry of the oligotrophic tailings materials inhibited both the extraction and amplification of nucleic acids. Insufficient quality reads ( $<5881$ reads) were obtained from ten samples (QB- $t_{3}-2$, QB- $t_{6}-2$, QB- $t_{12}-3$, TC- $t_{3}-1$, TC- $t_{12}-3$, TO- $t_{0}-1$, TO$t_{3}-3$, TO- $t_{6}-1$, TO- $t_{6}-2$, TO- $t_{12}-1$ ), thus these samples were removed from further analysis. The number of mesocosm replicates at each time point with sufficient quality reads for analysis is indicated in Table 2 along with the number of reads per sample (ranging from $6,125$ to 27,257$)$. The median sequence length was $151 \mathrm{bp}$. Read number was significantly higher for compost-amended treatments $(p<0.05)$ than the unamended tailings.

All sequences were classified into 2,364 OTUs. Approximately 97\% of the sequences corresponded to bacterial populations and the remaining $3 \%$ to archaeal populations. Rarefaction curves indicated that TO communities were well sampled, but the full diversity was not captured from the TC and QB treatments (Fig. 1A). Diversity dynamics were distinct for each of the treatments (Shannon Index, Table 2). TO demonstrated a progressive decrease in diversity followed by a rebound at $t_{12}$ to a level greater than that of $t_{0}$ (Table 2). Diversity trends corresponded to a concurrent decrease in $\mathrm{pH}$ and increase in pore water Fe 
and As concentrations, suggesting that active weathering and acidification of unamended pyritic tailings selected for a less diverse microbial community. The diversity rebound observed at $t_{12}$ was concurrent with a stabilization of both $\mathrm{pH}$ and pore water $\mathrm{Fe}$ concentration (Table 1). Compost amendment increased OTU richness 4-fold at $t_{0}$ and Shannon diversity $(H)$ remained relatively stable for 6 months (Table 2 ). After $t_{6}$, a large drop in diversity was observed that was concurrent with a $\mathrm{pH}$ decrease to 3.44. Interestingly, the final TC $\left(t_{12}\right)$ community richness was equal to that of the TO treatment, despite the initial 4-fold higher community richness. Quailbush plant establishment, on the other hand, sustained microbial community richness and the final QB OTU-richness was 2-fold higher than that of TO and TC.

\subsection{Treatment effects on microbial community phylogenetic composition}

Analysis of Similarities (ANOSIM) and Non-Metric Multidimensional Scaling (NMDS) were used to track changes in community phylogenetic composition in response to temporal pyrite weathering processes and reclamation treatment. ANOSIM revealed that the $\beta$ diversity of the TO community was significantly different from both the TC and QB across all time periods (Table 3 ). The NMDS plots reveal temporal changes in community composition for all treatments (Fig. 2). Despite the lack of significant difference in phylogenetic composition between TC and QB, the NMDS plot indicates that the communities generally diverged after $t_{0}$. The temporal changes in phylogenetic composition indicated by these results parallel the previously published community structural changes observed using DGGE analysis (Valentin-Vargas et al., 2014).

Phylogenetic community profiles were further analyzed to profile the distinct community dynamics associated with each treatment. OTUs identified from all treatments revealed broad distribution among 21 phyla and 7 candidate phyla (Supplementary Fig. 1), however the majority ( $\geq 90 \%$ ) were classified as one of just 5 phyla: Proteobacteria (including Alpha, Beta and Gamma classes), Actinobacteria, Firmicutes, Nitrospirae, and Euryarchaeota (Fig. 1B). An OTU heat map comparing the dominant taxa from TC/QB and TO communities at $t_{0}$ (filtered to remove all taxa with $<3 \%$ relative abundance at $t_{0}$ ) reveals that a diverse community of phylotypes was introduced with compost amendment (Fig. 3). In fact, $50 \%$ of the TC/QB taxa at $t_{0}$ are not present in the TO community. These taxa belonged to diverse groups including Actinobacteria, Bacteroidetes, Firmicutes, Gemmatimonadetes, Alphaproteobacteria and Gammaproteobacteria. The heat map also reveals the heterogeneity of the starting materials (homogenized in a cement mixer prior to initiating the experiment). Specifically, the TC- $t_{0}-3$ community composition appears intermediate to that of the other TO and TC samples. Presumably, this is due to a lower percentage of compost in this sample relative to the other two TC replicates. Thus, compost amendment provided a slightly heterogeneous inoculum that increased community richness and introduced an abundance of new taxa.

\subsection{Treatment-specific temporal dynamics of Fe- and S-oxidizing populations}

The controlled mesocosm experimental design allowed distinct population dynamics of Fe/S-oxidizing bacteria and archaea to be associated with different reclamation treatments during the weathering of pyritic mine tailings. Seven previously characterized Fe/S- 
oxidizing taxa (Baker and Banfield, 2003; Mahmoud et al., 2005; Goltsman et al., 2009; Hallberg, 2010; Hallberg and Johnson, 2001; Schippers et al., 2010; Chen et al., 2013; Watling et al., 2008; Yahya et al., 2008; Korehi et al., 2013) were present in the TO community at $t_{0}$. These seven phylotypes are referred to as the Fe/S-oxidizers for the remainder of this paper. These oxidizers include six OTUs with average abundances $>1 \%$ in the initial tailings material (Fig. 3; Thiomonas, Thiobacillus, Sulfobacillus, Alicyclobacillus, Acidithiobacillus, and Leptospirillum) and Ferroplasma with an average relative abundance of $0.2 \%$. Collectively, the Fe/S-oxidizing taxa represented $51 \% \pm 11 \%$ of the initial TO community. The relative cumulative abundance of these Fe/S-oxidizers in the TO treatment fluctuated from $45 \%$ to $58 \%$ to $24 \%$, at $t_{3}, t_{6}$, and $t_{12}$, respectively. Of note was the fact that the minimum abundance corresponded to the time point when weathering had slowed as indicated by stabilization of pore-water $\mathrm{pH}$ and $\mathrm{Fe}$ concentration.

A temporal progression of $\mathrm{Fe} / \mathrm{S}$-oxidizing phylotypes was observed in the TO microbial community. Thiomonas $(16 \%-30 \%)$ and Thiobacillus (2\% to $29 \%)$ were most abundant at $t_{0}$ and $t_{3}$ at $\mathrm{pH}$ values of 4.98 and 3.71 . In contrast, at $t_{6}$ and $t_{12}(\mathrm{pH} \leq 2.51)$, both genera were below detection in all samples with the exception of one $t_{12}$ replicate (Thiobacillus relative abundance $=4.2 \%$ ). Alicyclobacillus followed a similar pattern with highest abundance at $t_{0}$ and $t_{3}$ (relative abundance of $0.8-4.3 \%$ ), followed by a decrease below $0.05 \%$ for the remainder of the experiment. Leptospirillum relative abundance, on the other hand, increased during the experiment from $\leq 2 \%$ at $t_{0}$ and $t_{3}$, to maximum abundances of $29 \%-49 \%$ at $t_{6}$ and $t_{12}$. Ferroplasma demonstrated a similar pattern with relative abundances less than $1 \%$ at $t_{0}$ and $t_{3}$ followed by higher abundances in the second half of the study (highs of 7.4\%-7.8\%). Interestingly, the relative abundance of Sulfobacillus remained fairly constant throughout the experiment $(2.7 \% \pm 1.2 \%$, with a range of $0.6 \%-4.1 \%)$. The relative abundances of these phylotypes in Fig. 1B are as follows: Thiomonas and Thiobacillus represent $88.5 \%$ and $75 \%$ of the Betaproteobacteria at TO- $t_{0}$ and TO- $t_{3}$, respectively; Leptospirillum comprise $100 \%$ of the Nitrospirae at TO- $t_{6}$ and TO- $t_{12}$; and Ferroplasma represent $70 \%$ and $62 \%$ of the Euryarcheota at TO- $t_{6}$ and TO- $t_{12}$, respectively. Thus, a progression was observed from communities dominated by Thiomonas, Thiobacillus, and Alicyclobacillus at $\mathrm{pH}$ values above 3.5 to Leptospirillum-and Ferroplasma-dominated communities at $\mathrm{pH} \leq 2.5$. In fact, for all treatments, an inverse linear relationship was observed between the relative abundance of Leptospirillum and $\mathrm{pH}\left(R^{2}=\right.$ $0.529 ; p=0.011$ ).

Compost amendment and plant establishment had significant and distinct impacts on the dynamics of the $\mathrm{Fe} / \mathrm{S}$-oxidizing community. Compost-amendment was associated with an immediate reduction in relative abundance of Fe/S-oxidizers from $51 \% \pm 11 \%$ (TO) to $12 \%$ $\pm 15 \%$ (Fig. 3). A temporal increase in the TC Fe/S-oxidizers then followed over the remainder of the experiment with a maximum of $60 \%$ at $t_{12}$ when pore water $\mathrm{pH}$ was most acidic ( $\mathrm{pH}$ 3.44). As was observed in the TO treatment, the relative abundance of $\mathrm{Fe} / \mathrm{S}$ oxidizers was highest when pore water $\mathrm{pH}$ first reached the minimum. In contrast, plant establishment had a strong control on the relative abundance of Fe/S oxidizers. For QB, $\mathrm{Fe} / \mathrm{S}$-oxidizer relative abundance at each time point for QB was 12\%, 13\%, 9.5\% and $28 \%$ at $t_{0}, t_{3}, t_{6}$, and $t_{12}$, respectively, and the $\mathrm{pH}$ never decreased below 4.7 . Thus, plant establishment proved a more effective reclamation treatment than compost alone. 
In the TC treatment, Thiobacillus alone was dominant at $t_{3}(38 \% \pm 8 \%$ relative abundance; $\mathrm{pH}$ 6.27), then decreased in abundance progressively from $t_{6}$ to $t_{12}$, with decreasing $\mathrm{pH}$. Unlike TO, the relative abundance of Thiomonas never exceeded $2 \%$. At $t_{6}$ and $t_{12}$ the dominant TC taxa were variable between replicates and included Leptospirillum (16\% $\pm 1 \%)$, Acidithiobacillus $(17 \% \pm 20 \%)$, and Ferroplasma $(5 \% \pm 11 \%)$. Thus, a unique component of the TC Fe/S-oxidizing communities, relative to TO, was the comparative absence of Thiomonas at the early time periods and an elevated abundance of Acidithiobacillus in samples collected during the final 6 months of the experiment. Acidithiobacillus relative abundance in the TO treatment decreased from $2.6-8.5 \%$ relative abundance during the first half of the experiment to less than $1 \%$ at $t_{12}$, when Leptospirillum was the most abundant Fe-oxidizer. Recall that pore water DOC and TDN concentrations (Table 1) for TC mesocosms during the final six months were 25- to 50-fold higher than those of the TO treatment. Both Acidithiobacillus and Leptospirillum are chemolithoautotrophs, however Leptospirillum is known to be more sensitive to organic carbon (Johnson and Hallberg, 2009; Santofimia et al., 2013). We hypothesize that elevated DOC levels in the TC treatment created dynamics that allowed Acidithiobacillus to become competitive with Leptospirillum. Thus, the Fe/S-oxidizing microbial assemblage driving rapid acidification in TC was distinct from that of TO. The Alicyclobacillus abundance pattern in TC was the reverse of that observed in the TO treatment. The relative abundance was less than $0.5 \%$ for the first 6 months when $\mathrm{pH}$ was greater than 6 . Its abundance then increased to $2 \%$ at $t_{12}$ with decreasing $\mathrm{pH}$. Thus, the exact niche occupied by Alicyclobacillus spp. cannot be determined from this experiment.

In the QB treatment, Thiobacillus relative abundance ranged from $2 \%$ to $27 \%$ when $\mathrm{pH}$ levels were greater than 5 , then decreased below $2.5 \%$ when $\mathrm{pH}$ decreased to 4.7 .

Thiomonas relative abundance in QB never exceeded 2\%, as was observed for TC. The QB microbial community dynamics were unique in that Leptospirillum remained below $0.1 \%$ relative abundance until $t_{12}$, at which time a maximum relative abundance of $5.3 \%$ was detected. Acidithiobacillus and Ferroplamsa remained below $0.2 \%$ until $t_{12}$ when maximum relative abundances of $32 \%$ and $7.6 \%$, respectively, were observed. Pore-water DOC levels at $t_{6}$ were twice as high in QB as TC which may have limited the growth of both of the Feoxidizing chemoautotrophs, Acidithiobacillus and Leptospirillum during the first half of the experiment. Sulfobacillus and Alicyclobacillus remained below 2.5\% in TC and QB for the duration of the experiment.

\subsection{Key microbial taxa distinguishing the different treatments}

The Similarity Percentage (SIMPER) (Table 4) and the Linear Discriminant Analysis (LDA) Effect Size (LEfSe) methods were employed to identify the most significant taxa distinguishing the microbial communities associated with each treatment. The SIMPER analysis identifies the specific OTUs that contribute most to the average dissimilarity between treatments (weights the abundance of individual taxa), whereas LDA LEfSe (Segata et al., 2011) selects statistically significant microbial indicators uniquely enriched under each treatment condition (weights taxon uniqueness rather than overall abundance). SIMPER (Table 4) identified Leptospirillum spp. as most significant in explaining the overall differences between TO and the amended treatments. The relatively high abundance 
of Thiobacillus spp. differentiated TC most from the TO and QB treatments. In turn, the high and sustained abundance of species from the Xanthomonadaceae (93\% Dyella spp.) and Micrococcaceae (91\% Arthrobacter spp.) families in QB differentiated this treatment from the TO and TC treatments. The abundance profiles of Dyella spp. are particularly intriguing. This taxon was highly abundant in the initial tailings microbial community (Fig. 3 ), increased to an average of $16 \%$ relative abundance by $t_{3}$ in TO, then decreased below detection at $t_{6}$ when the $\mathrm{pH}$ decreased to 2.51 . Similarly, Dyella average relative abundance was $6 \%$ and $16 \%$ in the TC treatment at $t_{3}$ and $t_{6}$, respectively, but dropped below $1 \%$ at $t_{12}$ when the $\mathrm{pH}$ decreased to 3.44. In contrast, the average relative abundance of this group in QB peaked at $22 \%$ at $t_{3}$ and remained greater than $10 \%$ through the end of the experiment under conditions of $\mathrm{pH} \geq 4.74$. In summary, Dyella appears to be a significant, $\mathrm{pH}$-sensitive contributor to the tailings microbial community, but the functional significance of this taxon is unknown. The Micrococcaceae family, on the other hand was not detected in the initial tailings community, but was present at $0.02 \%$ and $0.97 \%$ in two of the $t_{0} \mathrm{TC} / \mathrm{QB}$ samples. This family increased in abundance in $\mathrm{QB}$ at $t_{3}$ and attained a maximum average relative abundance of $17 \%$ at $t_{6}$.

Using the five most abundant phyla, LEfSe identified 33 taxa at the family level that distinguished the treatments with LDA scores greater than 2 (Fig. 4A and 4B). The QB treatment had the greatest abundance of statistically unique taxa. In addition, the majority of the taxa associated with TO and 50\% of those associated with TC belonged to the Firmicutes phylum, whereas the QB taxa belonged to Actinobacteria, Alphaproteobacteria and Betaproteobacteria. The Micrococcaceae family had the highest LDA score of all taxa, being most abundant in QB. A full LEfSe analysis using all 28 phyla analyzed to the genus level revealed that the most significant Micrococcaceae taxa were primarily Arthrobacterspp. (Supplementary Fig. 2). In general, heterotrophic species of Actinobacteria and Proteobacteria contributed greatly to the $\beta$-diversity differences between QB and the TO and TC treatments (Fig. 2).

\section{Discussion}

Results from the controlled mesocosm experiment provide an excellent window into the complex and fluid dynamics of microbial communities driving acidification of pyritic tailings under a gradient of environmental conditions. In previous results from this mesocosm study, CCA indicated that temporal changes in microbial community structure are associated with distinct environmental variables specific to each of the mine tailings treatments (Valentín-Vargas et al., 2014). Here we demonstrate that these temporal changes reflect key transitions in both the diversity and phylogenetic composition of the associated microbial communities. Concurrent changes in the mesocosm pore-water chemistry indicated that observed transitions in the microbial communities influenced weathering rates of pyritic tailings materials.

\subsection{Treatment effects on microbial diversity}

The results reveal that compost amendment provided a diverse microbial inoculum and that QB plant establishment enhanced the sustainability of that inoculum. Compost amendment 
increased the microbial community richness 4 -fold, which corresponded to a $75 \%$ reduction in Fe/S-oxidizer abundance, however the final TC diversity decreased to that of the TO treatment. In contrast, the final QB microbial community richness was twice that of TO and $\mathrm{TC}$, the $\mathrm{pH}$ never decreased below 4.7 and the maximum relative abundance of $\mathrm{Fe} / \mathrm{S}$ oxidizers was held to just $28 \%$. Previous results have shown that quailbush and buffalo grass have the ability to alkalinize the rhizosphere environment (Solís-Dominguez et al., 2012) which may enhance the buffering capacity of the compost and facilitate the survival of the introduced microbial populations. Additional plant species were not tested in the previous study, however this capacity may be important to reclamation success and the alkalinization capacity of candidate plants could easily be assessed using the screening test described (Solís-Dominguez et al., 2012). A parallel field study at the IKMHSS site, demonstrated that plant establishment in compost-amended tailings sustained neutrophilic heterotrophic bacterial populations four-orders of magnitude greater than the unseeded and unamended tailings for the duration of the three-year experiment (Gil-Loaiza et al., 2016). A number of additional phytostabilization studies have demonstrated that successful plant establishment of mine tailings is associated with significant increases in the abundance of heterotrophic microbial populations (Li et al, 2015; Mendez et al., 2007; Solís-Dominguez et al., 2012) and that bioaugmentation of microbial communities leads to natural colonization of more diverse plant communities (Zornoza et al., 2017). In the mesocosm study, a decline in QB health observed at $t_{12}$ was associated with a sharp increase in the relative abundance of Fe/Soxidizing populations (28\%) and a concurrent 100-fold increase in pore-water Fe concentration. Thus, successful control of acidification processes relies on the sustainability of introduced vegetation. These results suggest addition of lime with the compost could augment the compost proton consumption capacity and enhance plant establishment to prevent acidification.

The results reveal that a critical property of the compost amendment is the associated microbial inoculum. Zornoza et al. (2017) amended both acidic and neutral tailings with pig manure, sewage sludge and a commercial microbial formulation. The study found that pig manure was more successful than sewage sludge, and concluded that the selection of organic material is fundamental to soil development and natural plant colonization. Thus, future research should evaluate the significance of the microbial profiles associated with different organic amendments to the success of plant establishment under diverse environmental conditions.

\subsection{Treatment effects on phylogenetic composition}

Pore water chemistry combined with tailings microbial phylogenetic analysis revealed that the weathering of pyritic mine tailings is associated with a temporal progression of Fe/Soxidizing bacteria and archaea. The TO community was initially dominated by Thiomonas, Thiobacillus, and Alicyclobacillus at $\mathrm{pH}$ values greater than 3.5, and then transitioned to a more acid-tolerant community dominated by Leptospirillum and Ferroplasma at $\mathrm{pH} \leq 2.5$. This pattern supports the previous observation that Thiobacillus spp. are moderately acidophilic Fe/S-oxidizing bacteria that generally prefer $\mathrm{pH}$ levels >3.5 (Chen et al., 2013; Korehi et al., 2014). Unique to TO was the dominance of the moderately-acidophilic Thiomonas spp. during the first three months of the experiment (16-30\% relative 
abundance), a phylotype that was present at just $2 \%$ or less in the TC and QB treatments. Thiomonas spp. is well-known for its capacity to utilize arsenic as an electron donor to generate energy (Duquesne et al., 2008; Bryan et al., 2009; Hallberg, 2010). Pore-water As concentration for TO was generally 10 -fold higher than that of TC/QB at any given time point. The data suggest that this phylotype influenced As mobilization more significantly in the unamended tailings, than in amended treatments.

The transition to the more acid-tolerant Leptospirillum- and Ferroplasma-dominated communities was associated with rapid decreases in $\mathrm{pH}$ and increases in pore-water $\mathrm{Fe}$ and As concentrations. The pore-water chemistry revealed that weathering rates were highest when Leptospirillum was most abundant. Leptospirillum is a well-characterized acidophilic, Fe-oxidizer commonly present in acid mine drainage biofilms (Goltsman et al., 2009). The role of Ferroplasma is less clearly understood. The metabolic potential of Ferroplasma includes aerobic ferrous iron oxidation, anaerobic ferric iron reduction using Fe(III) as a terminal electron acceptor with the capacity to dissolve Fe(III) hydroxides, and both autotrophic and heterotrophic metabolisms (Ziegler et al., 2013; Schippers et al., 2010). Peak abundances of this group were limited to isolated occurrences during the second half of the experiment.: TO-3 at $t_{6}(7.4 \%)$; TO-2 at $t_{12}(7.8 \%)$; TC-3 at $t_{6}(25 \%)$; and QB-1 at $t_{12}$ (7.6\%). The $\mathrm{pH}$ values associated with these four time points ranged from 2.5 to 6.1 , suggesting that Ferroplasma are acid-tolerant, but are also competitive under less acidic conditions. Their proliferation at $t_{6}$ and $t_{12}$ could be associated with the increasing availability of $\mathrm{Fe}(\mathrm{III})$ as an electron acceptor resulting from $\mathrm{Fe}$-oxidation processes (Korehi et al., 2013) or the increasing abundance of precipitated Fe(III) hydroxides. However, the inconsistent abundance profile of this group limits our ability to predict their specific niche and role in the mesocosms.

The observed temporal evolution of the Fe/S-oxidizing community in this study can be compared to a number of recent studies that have analyzed mine-waste samples collected along $\mathrm{pH}$ gradients selected to represent different stages of pyrite oxidation (Chen et al., 2013; Chen et al., 2014; Korechi et al., 2014; Liu et al., 2014). Results from these surveys indicate similar patterns to those documented in the present mesocosm experiment. Bacterial phylotype richness and phylogenetic diversity were correlated positively with $\mathrm{pH}$ (Chen et al., 2014; Liu et al., 2014) and shifts in microbial community composition were observed along $\mathrm{pH}$ gradients. These patterns led researchers to speculate that different taxa are associated with different stages of oxidation and that $\mathrm{pH}$ shapes microbial community composition during pyrite oxidation (Chen et al., 2013; Chen et al., 2014; Korechi et al., 2014; Liu et al., 2014). One greenhouse study evaluating samples representing different stages of pyrite oxidation (Chen et al., 2014) found that communities at $\mathrm{pH}>5$ were comprised of OTUs belonging to Tumebacillus, Thiobacillus, Thiomonas, Alicyclobacillus, Ferroplasma, and Dyella; communities at pH 3-5 were dominated by Alicyclobacillus; and those at $\mathrm{pH}<3$ contained Ferroplasma, Leptospirillum, Sulfobacillus, Acidithiobacillus, and Alicyclobacillus. Similarly, a study examining six field samples collected from a $\mathrm{Pb} / \mathrm{Zn}$ mine with $\mathrm{pH}$ values ranging from 7.5 to 1.8 (Chen et al., 2013) identified members of

Thiobacillus at $\mathrm{pH}$ levels of 6.4 and 7.5, whereas under more acidic conditions, communities were dominated by either Ferroplasma (pH 1.8 and 2.1) or Acidithiobacillus, Leptospirillum, Ferroplasma, and Sulfobacillus (pH 2.4). 
Taken together, the results from this study combined with previous work strongly support the hypothesis that pyrite weathering is driven by a succession of increasingly more acidophilic microbial communities that evolve in association with decreasing $\mathrm{pH}$ and progressive changes in the tailings geochemistry during the weathering process. Here we show that reclamation treatment can impede the evolution of this highly efficient $\mathrm{Fe} / \mathrm{S}$ oxidizing community. In the TC treatment, the acidophililc Fe/S-oxidizer community shifted to a community that included Acidithiobacillus along with Leptospirillum, and Ferroplasma. As explained previously, Acidithiobacillus was present in TO at $t_{0}$ and $t_{3}$, but decreased to $<1 \%$ abundance at $t_{6}$ and appeared unable to compete with the dominant Leptospirillum community. QB establishment further impacted the Fe/S-oxidizer successional community evolution. In the QB treatment, Leptospirillum never exceeded 5\% relative abundance and Acidithiobacillus did not become abundant until $t_{12}$. These results suggest that members of the Acidithiobacillus and Leptospirillum genera contributed significantly to the acidification of the tailings under highly acidic conditions, but exploited different niches as defined by environmental conditions (e.g. $\mathrm{pH}$, plants, DOC levels). Leptospirillum appeared to have a competitive advantage at low $\mathrm{pH}$ and under low DOC levels, but was inhibited in the QB treatment under conditions that Acidithiobacillus spp. could exploit. Future reclamation treatments must be eco-engineered to prevent proliferation of Leptospirillum and Acidithiobacillus phylotypes. Increases in abundance of either of these phylotypes can serve as a bioindicator of negative progress in soil development.

The QB treatment provides an opportunity to evaluate associations between heterotrophic microbial populations introduced with the compost and successful plant establishment. The composition of this community can guide future reclamation efforts to eco-engineer reclamation treatments or select appropriate organic amendments. The QB community included a diversity of heterotrophs belonging to Actinobacteria, Alphaproteobacteria, and Betaproteobacteria that differentiated it from the TO and TC microbial communities. We hypothesize that the abundance and diversity of the heterotrophic bacterial species associated with QB plant establishment serves as a control on the proliferation of $\mathrm{Fe} / \mathrm{S}$ oxidizing autotrophic species. The abundance of organic carbon supplied from compost and root exudates (as indicated by high pore-water DOC levels), stimulates growth of heterotrophic populations giving them a competitive advantage over the autotrophic oxidizers. A similar pattern was observed in the analysis of samples collected from vegetated and bare copper mine tailings at a mine site in China (Li et al., 2016b). Vegetated areas were characterized by reduced pyrite oxidation and lower abundances of Acidithiobacillus spp. and Leptospirillum spp. as compared to bare tailings ( $\mathrm{Li}$, et al., 2016b).

In the present mesocosm study, the LEFSe analysis identified Arthrobacter spp. as the most significant phylotype differentiating QB from the other treatments. Arthrobacter is a genus of mostly neutrophilic plant growth promoting (PGP) bacteria that includes acid-tolerant (De Boer and Kowalchuk, 2001; Bashan and de-Bashan, 2005) and metal-tolerant species (Margesin and Schinner, 1996; Grandlic et al., 2008). PGP bacteria promote plant growth through a wide array of ecological interactions (Marschner, 2007; Grandlic et al., 2009). Potential PGP mechanisms of Arthrobacter spp. include: ammonia oxidation (Kouki et al., 2011; Matsuno et al., 2013), nitrogen fixation (Gtari et al., 2012; Yu et al., 2012), 
phosphorous solubilization (Grandlic et al., 2008; Saharan and Nehra, 2011), phytohormone production and degradation (Grappelli and Rossi, 1981; Dodd et al., 2010), management of environmental stress (Grandlic et al., 2008; Dimkpa et al., 2009), biocontrol of plant pathogens (Dimkpa et al., 2009; Scavino and Pedraza, 2013), and biosynthesis of siderophores (Grandlic et al., 2008; Scavino and Pedraza, 2013). Significantly, Grandlic et al. $(2008,2009)$ demonstrated enhanced biomass production of quailbush grown in pyritic mine tailings following inoculation with three Arthrobacter strains. Enrichment of phylotypes with PGP potential is an important positive outcome of plant establishment. The presence of this group at low concentrations in TC at $t_{0}$ and $t_{3}(0.25 \%-4.8 \%)$ and its virtual absence from TO suggests that compost was a source of Arthrobacter spp. in the mesocosms and that this species should be targeted in future eco-engineering efforts.

Finally, the SIMPER analysis also identified Xanthomonadaceae (93\% Dyella spp.) as a key family differentiating QB from the other treatments. The significance of this phylotype should be considered due to its frequent abundance in mine waste (Chen, et al., 2014; González-Toril et al., 2011; Lu et al., 2010; Ziegler et al., 2013) and AMD sediments (Delavat et al., 2012) and its poorly understood functional potential. Ziegler et al. (2013) found that the fourth most abundant taxon in a $\mathrm{FeS}_{2}$ oxidizing mine biofilm belonged to Xanthomonadaceae family. This family appeared to originate from the initial TO community, retained a relative abundance of 10-30\% throughout the QB treatment, and demonstrated pH sensitivity below 3.5. First described by Xie and Yokota (2005), this genus currently includes 11 described species (http://www.bacterio.net/dyella.html). Virtually all species have been isolated from soil, most are strict heterotrophs, and all are aerobic neutrophiles. Some have been shown to tolerate acidic conditions to $\mathrm{pH} 4$ (Weon et al., 2009; Zhao et al., 2013). Dyella thiooxydans has been described as a facultative chemolithoautothotroph capable of oxidizing reduced sulfur compounds at circumneutral $\mathrm{pH}$ (Anandham et al., 2011). Several additional Dyella strains have been linked to chemolithotrophic oxidation of iron and sulfur compounds at circumneutral $\mathrm{pH}$ (Anandham et al., 2008; Emerson et al., 2012; Lin et al., 2012a; Lin et al., 2012b; Roden et al., 2012; Uroz et al., 2009). Reports from Lin et al. (2012b) on the enrichment of Dyella spp. under neutrophilic, microaerophilic, iron-oxidizing conditions from samples collected from a coastal catchment suggest that these aerobic microbes function by colonizing microoxic niches. A second report from Roden et al. (2012) detected Dyella spp. in samples collected from a groundwater seep (pH 6.47) with elevated levels of Fe (III) oxides and suggested that the bacteria mediated the anaerobic/microaerobic oxidation of iron-sulfides at circumneutral $\mathrm{pH}$. The functional role of Dyella in Fe/S-oxidizing communities is unknown, but the abundance of this phylotype in the QB treatment and its consistent presence in diverse $\mathrm{Fe} / \mathrm{S}$ oxidizing communities supports the need for future research efforts directed at elucidating the potential role of Dyella in in situ pyrite oxidation of mine tailings.

\section{Conclusions}

To our knowledge, this study provides the first documentation of temporal microbial community dynamics during acidification of pyritic mine tailings under different treatment conditions. Two key results were revealed by this study. First, this study confirms that the acidification of pyritic mine tailings is associated with a temporal progression of bacterial 
and archaeal phylotypes, beginning with $\mathrm{pH}$ sensitive Thiobacillus and Thiomonas species and progressing to communities dominated by acid-tolerant Leptospirillum and Ferroplasma species. This confirms results from previous single time-point $\mathrm{pH}$ surveys of mine tailings materials, presumed to be at distinct pyrite oxidation stages based on the mineralogy of the materials (Chen, et al., 2014; Chen, et al., 2013; Korechi et al., 2014). Second, compost amendment and plant establishment disrupt the "optimal" successional development of Fe/Soxidizing microbial communities. However, compost amendment provided only a temporary control on the acidification process; whereas plant establishment stimulated growth of heterotrophic bacterial species and controlled the relative abundance of Fe/S-oxidizers. Specifically, QB establishment prevented the proliferation of Leptospirillum spp. for the duration of the experiment. We propose that both elevated DOC levels from compost and plant root exudates and the diversity of the heterotrophic community control the abundance and activity of Fe/S-oxidizers in the QB treatment. The results of this study confirm that microbial community dynamics are integral to phytostabilization success and suggest the potential for an eco-engineered microbial contribution to reclamation strategies. Specifically, a microbial amendment could be developed that facilitates the proliferation of PGP heterotrophic microbial communities to sustain plant communities and serve as a control on the proliferation of the highly efficient Fe/S-oxidizing phylotypes (e.g. Leptospirillum,

Acidithiobacillus, and Ferroplasma).

\section{Supplementary Material}

Refer to Web version on PubMed Central for supplementary material.

\section{Acknowledgments}

This research was supported by the National Institute of Environmental Health Sciences [grant numbers P42 ES04940, R01 ES017079]. Additional support for AVV was provided by the American Society for Microbiology and Alfred P. Sloan Foundation. Special thanks to Steven Schuchardt for providing access to IKMHSS, Scott White for coordinating the fieldwork, Corin Hammond for assistance with the greenhouse setup and all the staff involved in the collection of the tailings and the greenhouse work. Thanks to Virginia Rich for coordination of DNA sequencing.

\section{References}

Akcil A, Koldas S. Acid Mine Drainage (AMD): causes, treatment and case studies. J Clean Prod. 2006; 14:1139-1145.

Anandham R, Indiragandhi P, Madhaiyan M, Ryu KY, Jee HJ, Sa TM. Chemolithoautotrophic oxidation of thiosulfate and phylogenetic distribution of sulfur oxidation gene (soxB) in rhizobacteria isolated from crop plants. Res Microbiol. 2008; 159:579-589. [PubMed: 18832027]

Anandham R, Kwon SW, Gandhi PI, Kim SJ, Weon HY, Kim YS, et al. Dyella thiooxydans sp. nov., a facultatively chemolithotrophic, thiosulfate-oxidizing bacterium isolated from rhizosphere soil of sunflower (Helianthus annuus L.). Int J Syst Evol Microbiol. 2011; 61:392-398. [PubMed: 20305058]

Baker BJ, Banfield JF. Microbial communities in acid mine drainage. FEMS Microbiol Ecol. 2003; 44:139-152. [PubMed: 19719632]

Bashan, Y., de-Bashan, LE. Bacteria: Plant growth-promoting. In: Hillel, D., editor. Encyclopedia of Soils in the Environment. 1. Oxford: Elsevier; 2005. p. 103-115.

Bokulich NA, Subramanian S, Faith JJ, Gevers D, Gordon JI, Knight R, Mills DA, Caporaso JG. Quality-filtering vastly improves diversity estimates from Illumina amplicon sequencing. Nature Methods. 2013; 10:57-59. [PubMed: 23202435] 
Bryan CG, Marchal M, Battaglia-Brunet F, Kugler V, Lemaitre-Guillier C, Lièvremont D, et al. Carbon and arsenic metabolism in Thiomonas strains: differences revealed diverse adaptation processes. BMC Microbiol. 2009; 9:127. [PubMed: 19549320]

Caporaso JG, Lauber CL, Walters WA, Berg-Lyons D, Lozupone CA, Turnbaugh PJ, et al. Global patterns of $16 \mathrm{~S}$ rRNA diversity at a depth of millions of sequences per sample. Proc Natl Acad Sci USA. 2011; 108:4516-4522. [PubMed: 20534432]

Caporaso JG, Lauber CL, Walters WA, Berg-Lyons D, Huntley J, Fierer N, et al. Ultra-high-throughput microbial community analysis on the Illumina HiSeq and MiSeq platforms. ISME J. 2012; 6:16211624. [PubMed: 22402401]

Chen LX, Li JT, Chen YT, Huang LN, Hua ZS, Hu M, Shu WS. Shifts in microbial community composition and function in the acidification of a lead/zinc mine tailings. Environ Microbiol. 2013; 15:2431-2444. [PubMed: 23574280]

Chen LY, Li JT, Chen YT, Hua ZS, Huang LN, Liu J, Xu B, Liao B, Shu WS. Biogeochemcial processes governing natural pyrite oxidation and release of acid metalliferous drainage. Environ Sci Tech. 2014; 48:5537-5545.

De Boer W, Kowalchuk GA. Nitrification in acid soils: micro-organisms and mechanisms. Soil Biol Biochem. 2001; 33:853-866.

Delavat F, Lett MC, Lièvremont D. Novel and unexpected bacterial diversity in an arsenic-rich ecosystem revealed by culture-dependent approaches. Biol Direct. 2012; 7:28. [PubMed: 22963335]

DeSantis TZ, Hugenholtz P, Larsen N, Rojas M, Brodie EL, Keller K, et al. Greengenes, a chimerachecked 16S rRNA gene database and workbench compatible with ARB. Appl Environ Microbiol. 2006; 72:5069-5072. [PubMed: 16820507]

Dhariwal A, Chong J, Habib S, King I, Agellon LB, Xia J. MicrobiomeAnalyst - a web-based tool for comprehensive statistical, visual and meta-analysis of microbiome data. Nucleic Acids Res. 2017; 45:W180-188.

Dimkpa C, Weinand T, Asch F. Plant-rhizobacteria interactions alleviate abiotic stress conditions. Plant Cell Environ. 2009; 32:1682-1694. [PubMed: 19671096]

Dodd IC, Zinovkina NY, Safronova VI, Belimov AA. Rhizobacterial mediation of plant hormone status. Ann Appl Biol. 2010; 157:361-379.

Dold B, Fontboté L. Element cycling and secondary mineralogy in porphyry copper tailings as a function of climate, primary mineralogy, and mineral processing. J Geochem Explor. 2001; 74:355.

Duquesne K, Lieutaud A, Ratouchniak J, Muller D, Lett MC, Bonnefoy V. Arsenite oxidation by a chemoautotrophic moderately acidophilic Thiomonas sp.: from the strain isolation to the gene study. Environ Microbiol. 2008; 10:228-237. [PubMed: 17894815]

Edgar RC. Search and clustering orders of magnitude faster than BLAST. J Gerontol. 2010; 26:24602461.

Emerson D, Roden E, Twining BS. The microbial ferrous wheel: iron cycling in terrestrial, freshwater, and marine environments. Front Microbiol. 2012; 3:383. [PubMed: 23118735]

Garris HW, Baldwin SA, Van Hamme JD, Gardner WC, Fraser LH. Genomics to assist mine reclamation: a review. Restor Ecol. 2016; 24:165-173.

Gil-Loaiza J, White SA, Root RA, Solís-Dominguez FA, Hammond CM, Chorover J, Maier RM. Phytostabilization of mine tailings using compost-assisted direct planting: translating greenhouse results to the field. Sci Total Environ. 2016; 565:451-461. [PubMed: 27183459]

Goltsman DSA, Denef VJ, Singer SW, VerBerkmoes NC, Lefsrud M, Mueller RS, et al. Community genomic and proteomic analyses of chemoautotrophic iron-oxidizing "Leptospirillum rubarum" (Group II) and "Leptospirillum ferrodiazotrophum" (Group III) bacteria in acid mine drainage biofilms. Appl Environ Microbiol. 2009; 75:4599-4615. [PubMed: 19429552]

González-Toril E, Aguilera A, Souza-Egipsy V, Pamo EL, España JS, Amils R. Geomicrobiology of La Zarza-Perrunal acid mine effluent (Iberian Pyritic Belt, Spain). Appl Environ Microbiol. 2011; 77:2685-2694. [PubMed: 21357431] 
Grandlic CJ, Mendez MO, Chorover J, Machado B, Maier RM. Plant growth-promoting bacteria for phytostabilization of mine tailings. Environ Sci Technol. 2008; 42:2079-2084. [PubMed: 18409640]

Grandlic CJ, Palmer MW, Maier RM. Optimization of plant growth-promoting bacteria-assisted phytostabilization of mine tailings. Soil Biol Biochem. 2009; 41:1734-1740. [PubMed: 20161141]

Grappelli A, Rossi W. The effect of phytohormones produced by Arthrobacter sp. on the phosphatase activity in plant roots. Folia Microbiol (Praha). 1981; 26:137-141. [PubMed: 7262713]

Gtari M, Ghodhbane-Gtari F, Nouioui I, Beauchemin N, Tisa LS. Phylogenetic perspectives of nitrogen-fixing actinobacteria. Arch Microbiol. 2012; 194:3-11. [PubMed: 21779790]

Hallberg KB. New perspectives in acid mine drainage microbiology. Hydrometallurgy. 2010; 104:448453.

Hallberg KB, Johnson DB. Biodiversity of acidophilic prokaryotes. Adv Appl Microbiol. 2001; 49:3784. [PubMed: 11757351]

Hammer $\emptyset$, Harper D, Ryan PD. PAST: paleontological statistics software package for education and data analysis. Palaeontolo Electron. 2001; 4:1-9.

Hayes SM, Root RA, Perdrial N, Maier RM, Chorover J. Surficial weathering of iron sulfide mine tailings under semi-arid climate. Geochim Cosmochim Acta. 2014; 141:240-257. [PubMed: 25197102]

Hayes SM, White SA, Thompson TL, Maier RM, Chorover J. Changes in lead and zinc lability during weathering-induced acidification of desert mine tailings: Coupling chemical and micro-scale analyses. Appl Geochem. 2009; 24:2234-2245.

Johnson DB, Hallberg KB. Acid mine drainage remediation options: a review. Sci Total Environ. 2005; 338:3-14. [PubMed: 15680622]

Johnson DB, Hallberg KB. Carbon, iron and sulfur metabolism in acidophilic micro-organisms. Adv Microb Physiol. 2009; 54:201-255. [PubMed: 18929069]

Kirby CS, Brady JAE. Field determination of Fe 2+ oxidation rates in acid mine drainage using a continuously-stirred tank reactor. Appl Geochem. 1998; 13:509-520.

Korehi H, Blöthe M, Sitnikova MA, Dold B, Schippers A. Metal mobilization by iron- and sulfuroxidizing bacteria in a multiple extreme mine tailings in the Atacama Desert, Chile. Environ Sci Technol. 2013; 47:2189-2196. [PubMed: 23373853]

Korehi H, Blöthe M, Schippers A. Microbial diversity at the moderate acidic stage in three different sulfidic tailings dumps generating acid mine drainage. Res Microbiol. 2014; 165:713-718. [PubMed: 25205555]

Kouki S, Saidi N, M'hiri F, Nasr H, Cherif H, Ouzari H, Hassen A. Isolation and characterization of facultative mixotrophic ammonia-oxidizing bacteria from constructed wetlands. J Environ Sci (China). 2011; 23:1699-1708. [PubMed: 22432266]

Krebs, CJ. Ecological Methodology. 2. Menlo Park, CA: Addison-Wesley; 1999.

Kuczynski J, Stombaugh J, Walters WA, González A, Caporaso JG, Knight R. Using QIIME to analyze 16S rRNA gene sequences from microbial communities. Curr Protoc Bioinformatics. 2011; Chapter 10(Unit 10.7)

Li X, Bond PL, Van Nostrand JD, Zhou J, Huang L. From lithotroph- to organotroph-dominant: directional shift of microbial community in sulphidic tailings during phytostabilization. Sci Rep. 2015; 5:12978. [PubMed: 26268667]

Li Y, Jia Z, Sun Q, Zhan J, Yang Y, Wang D. Ecological restoration alters microbial communities in mine tailings profiles. Nat Sci Rep. 2016a; 6:25193.

Li Y, Sun Q, Zhan J, Yang Y, Wang D. Vegetation successfully prevents oxidation of sulfide minerals in mine tailings. J Environ Manage. 2016b; 177:153-160. [PubMed: 27093236]

Lin C, Larsen EI, Larsen GR, Cox ME, Smith JJ. Bacterially mediated iron cycling and associated biogeochemical processes in a subtropical shallow coastal aquifer: implications for groundwater quality. Hydrobiologia. 2012a; 696:63-76.

Lin C, Larsen EI, Nothdurft LD, Smith JJ. Neutrophilic, microaerophilic Fe (II)-oxidizing bacteria are ubiquitous in aquatic habitats of a subtropical Australian coastal catchment. Geomicrobiol J.

2012b; 29:76-87. 
Liu J, Hua ZS, Chen LX, Kuang JL, Li SJ, Shu WS, Huang LN. Correlating Microbial Diversity Patterns with Geochemistry in an Extreme and Heterogeneous Environment of Mine Tailings. Appl Environ Microbiol. 2014; 80:3677-3686. [PubMed: 24727268]

Lu S, Gischkat S, Reiche M, Akob DM, Hallberg KB, Kusel K. Ecophysiology of Fe-cycling bacteria in acidic sediments. Appl Environ Microbiol. 2010; 76:8174-8183. [PubMed: 20971876]

Ma Y, Lin C. Microbial oxidation of $\mathrm{Fe}^{2+}$ and pyrite exposed to flux of micromolar $\mathrm{H}_{2} \mathrm{O}_{2}$ in acidic media. Sci Rep. 2013; 3:1979. [PubMed: 23760258]

Mahmoud KK, Leduc LG, Ferroni GD. Detection of Acidithiobacillus ferrooxidans in acid mine drainage environments using fluorescent in situ hybridization (FISH). J Microbiol Methods. 2005; 61:33-45. [PubMed: 15676194]

Margesin R, Schinner F. Bacterial heavy metal-tolerance- extreme resistance to nickel in Arthrobacter spp. strains. J Basic Microbiol. 1996; 36:269-282.

Marschner, P. Plant-microbe interactions in the rhizosphere and nutrient cycling. In: Marschner, P., Rengel, Z., editors. Soil Biology Vol 10: Nutrient Cycling in Terrestrial Ecosystems. Dordrecht: Springer; 2007. p. 159-182.

Matsuno T, Horii S, Sato T, Matsumiya Y, Kubo M. Analysis of nitrification in agricultural soil and improvement of nitrogen circulation with autotrophic ammonia-oxidizing bacteria. Appl Biochem Biotechnol. 2013; 169:795-809. [PubMed: 23274722]

Mendez MO, Glenn EP, Maier RM. Phytostabilization potential of quailbush for mine tailings. J Environ Qual. 2007; 36:245-253. [PubMed: 17215233]

Mendez MO, Maier RM. Phytostabilization of mine tailings in arid and semiarid environments-an emerging remediation technology. Environ Health Perspec. 2008; 116:278-283.

Mendez MO, Neilson JW, Maier RM. Characterization of a bacterial community in an abandoned semiarid lead-zinc mine tailing site. Appl Environ Microb. 2008; 74:3899-3907.

National Priority List (NPL). [accessed 9/22/2015] Iron King Mine and Humboldt Smelter. 2008. http://yosemite.epa.gov/r9/sfund/r9sfdocw.nsf/ViewByEPAID/AZ0000309013

Nelson KN, Neilson JW, Root RA, Chorover J, Maier RM. Abundance and activity of 16S rRNA, amoA and nifH bacterial genes during assisted phytostabilization of mine tailings. Int $\mathbf{J}$ Phytostabilizaton. 2015; 5:493-502.

Nordstrom DK, Southam G. Geomicrobiology of sulfide mineral oxidation. Rev Mineral. 1997; 35:361-390.

Paulson JN, Stine OC, Bravo HC, Pop M. Differential abundance analysis for microbial marker-gene surveys. Nature Methods. 2013; 10:1200-1202. [PubMed: 24076764]

Roden EE, McBeth JM, Blöthe M, Percak-Dennett EM, Fleming EJ, Holyoke RR, et al. The microbial ferrous wheel in a neutral pH groundwater seep. Front Microbiol. 2012; 3:172. [PubMed: 22783228]

Root RA, Hayes SM, Hammond C, Maier RM, Chorover J. Toxic metal(loid) speciation during weathering of iron sulfide mine tailings under semi-arid climate. Appl Geochem. 2015; 62:131149. [PubMed: 26549929]

Saharan BS, Nehra V. Plant growth promoting rhizobacteria: a critical review. Life Sci Med Res. 2011; 21:30.

Santofimia E, González-Toril E, López-Pamo E, Gomariz M, Amils R, Aguilera A. Microbial diversity and its relationship to physicochemical characteristics of the water in two extreme acidic pit lakes from the Iberian Pyrite Belt (SW Spain). PLoS ONE. 2013; 8:e66746. [PubMed: 23840525]

Scavino, AF., Pedraza, RO. The role of siderophores in plant growth-promoting bacteria. In: Maheshwari, DK.Saraf, M., Aeron, A., editors. Bacteria in Agrobiology: Crop Productivity. Berlin: Springer-Verlag; 2013. p. 265-285.

Schippers A, Breuker A, Blazejak A, Bosecker K, Kock D, Wright TL. The biogeochemistry and microbiology of sulfidic mine waste and bioleaching dumps and heaps, and novel Fe(II)-oxidizing bacteria. Hydrometallurgy. 2010; 104:342-350.

Segata N, Izard J, Waldron L, Gevers D, Miropolsky L, Garrett WS, Huttenhower C. Metagenomic biomarker discovery and explanation. Gen Biol. 2011; 12:R60.

Shu WS, Ye ZH, Zhang ZQ, Lan CY, Wong MH. Natural colonization of plants on five lead/zinc mine tailings in Southern China. Restor Ecol. 2005; 13:49-60. 
Solís-Domínguez FA, White SA, Hutter TB, Amistadi MK, Root RA, Chorover J, Maier RM. Response of key soil parameters during compost-assisted phytostabilization in extremely acidic tailings: effect of plant species. Environ Sci Technol. 2012; 46:1019-1027. [PubMed: 22191663]

Solís-Domínguez FA, Valentín-Vargas A, Chorover J, Maier RM. Effect of arbuscular mycorrhizal fungi on plant biomass and the rhizosphere microbial community structure of mesquite grown in acidic lead/zinc mine tailings. Sci Total Environ. 2011; 409:1009-1016. [PubMed: 21211826]

Uroz S, Calvaruso C, Turpault MP, Frey-Klett P. Mineral weathering by bacteria: ecology, actors and mechanisms. Trends Microbiol. 2009; 17:378-387. [PubMed: 19660952]

Valentín-Vargas A, Root RA, Neilson JW, Chorover J, Maier RM. Environmental factors influencing the structural dynamics of soil microbial communities during assisted phytostabilization of acidgenerating mine tailings: A mesocosm experiment. Sci Total Environ. 2014; 500:314-324. [PubMed: 25237788]

Watling HR, Perrot FA, Shiers DW. Comparison of selected characteristics of Sulfobacillus species and review of their occurrence in acidic and bioleaching environments. Hydrometallurgy. 2008; 93:5765.

Weon HY, Anandham R, Kim BY, Hong SB, Jeon YA, Kwon SW. Dyella soli sp. nov. and Dyella terrae sp. nov., isolated from soil. Int J Syst Evol Microbiol. 2009; 59:1685-1690. [PubMed: 19542132]

Xie CH, Yokota A. Dyella japonica gen. nov., sp. nov., a gamma-proteobacterium isolated from soil. Int J Syst Evol Microbiol. 2005; 55:753-756. [PubMed: 15774657]

Yahya A, Hallberg KB, Johnson DB. Iron and carbon metabolism by a mineral-oxidizing Alicyclobacillus-like bacterium. Arch Microbiol. 2008; 189:305-312. [PubMed: 18004545]

Yu X, Liu X, Zhu TH, Liu GH, Mao C. Co-inoculation with phosphate-solubilzing and nitrogen-fixing bacteria on solubilization of rock phosphate and their effect on growth promotion and nutrient uptake by walnut. Eur J Soil Biol. 2012; 50:112-117.

Zhao F, Guo XQ, Wang P, He LY, Huang Z, Sheng XF. Dyella jiangningensis sp. nov., a $\gamma-$ proteobacterium isolated from the surface of potassium-bearing rock. Int J Syst Evol Microbiol. 2013; 63:3154-3157. [PubMed: 23435246]

Ziegler S, Dolch K, Geiger K, Krause S, Asskamp M, Eusterhues K, et al. Oxygen-dependent niche formation of a pyrite-dependent acidophilic consortium built by archaea and bacteria. ISME J. 2013; 7:1725-1737. [PubMed: 23619304]

Zornoza R, Gómez-Garrido M, Martínez-Martínez S, Gómez-López MD, Faz A. Bioaugmentation in technosols created in abandoned pyritic tailings can contribute to enhance soil $\mathrm{C}$ sequestration and plant colonization. Sci Total Environ. 2017; 593-594:357-367. 


\section{Highlights}

- Semiarid, oxidative weathering drives acidification of pyrite-rich mine tailings

- Oxidative weathering is associated with a temporal evolution of $\mathrm{Fe} / \mathrm{S}$ oxidizers

- Acidification inhibits phytostabilization of pyritic, metalliferous tailings

- Plant establishment controlled the proliferation and activity of Fe/S-oxidizers

- Abundant plant growth promoting bacteria associated with quailbush establishment 

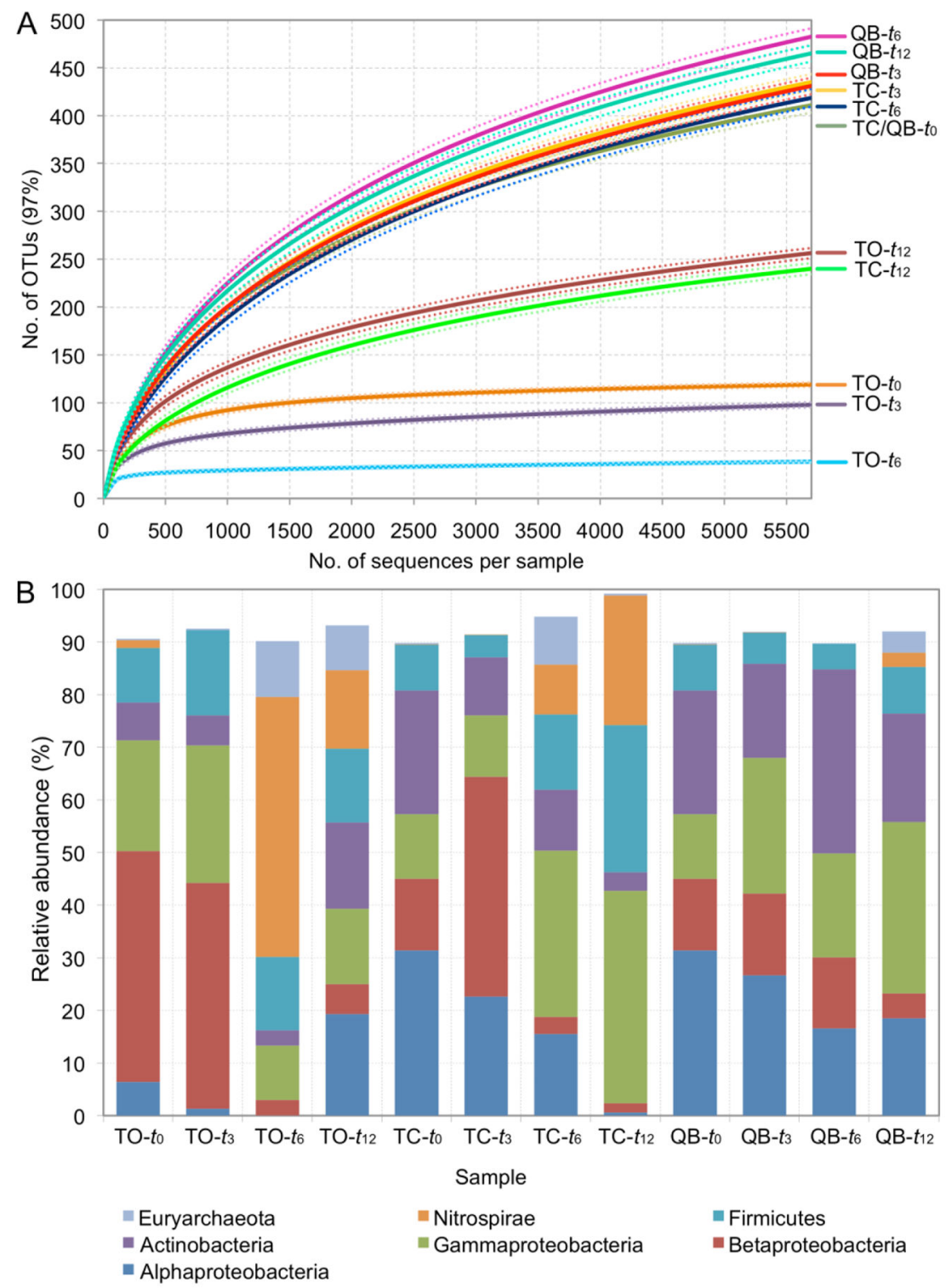

Figure 1.

Analysis of the rarefaction of OTU alpha diversity and the taxonomic assignment of OTUs. OTU assignments are based on $97 \%$ sequence similarity. (A) rarefaction curves for all the samples with iTag reads normalized to 5,700 sequences. Dashed lines (lighter color) around curves correspond to standard error (95\% confidence intervals). (B) the relative abundance of the 7 overall most abundant taxa (each taxon has multiple OTUs) for all the samples. These 7 taxa account for at least $\sim 90 \%$ of all OTUs detected per samples. 


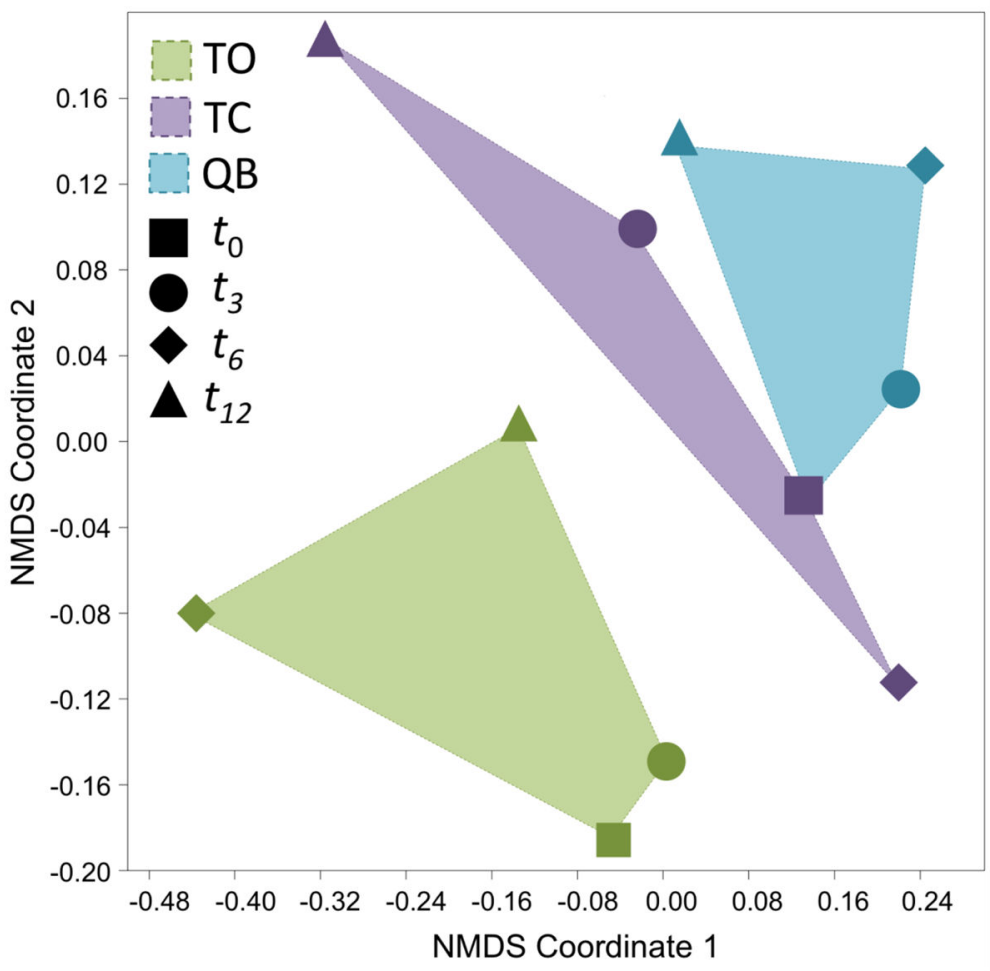

Figure 2.

Non-Metric Multidimensional Scaling (NMDS) ordination diagram of temporal variations in taxonomic community composition. The ordination is based on a Bray-Curtis distance matrix calculated from the relative abundance data of OTUs obtained from the iTag analysis. Each scatter point in the plot represents the structure of a microbial community in a particular treatment at a particular time point. The spatial separation between points approximates the similarity between their communities in terms of OTU composition. Stress: 0.0599 . 


\begin{tabular}{|c|c|c|c|c|c|}
\hline OTU Identification & TO- $t_{0}-2$ & TO- $t_{0}-3$ & TC- $t_{0}-1$ & TC- $t_{0}-2$ & TC- $t_{0-3}$ \\
\hline g__Thiomonas & 16.6 & 29.7 & 0.0 & 0.0 & 2.1 \\
\hline g__Dyella & 5.5 & 9.3 & 0.0 & 0.0 & 12.3 \\
\hline g_Pseudomonas & 3.0 & 7.9 & 0.0 & 0.3 & 0.2 \\
\hline g_Alicyclobacillus & 1.3 & 4.3 & 0.0 & 0.0 & 0.0 \\
\hline f__Phyllobacteriaceae & 0.0 & 4.2 & 0.5 & 0.6 & 0.6 \\
\hline f_Microbacteriaceae & 3.9 & 4.1 & 0.0 & 0.2 & 2.2 \\
\hline g__Sulfobacillus & 3.1 & 3.2 & 0.2 & 0.2 & 0.1 \\
\hline o__Acidoba cteriales & 0.0 & 2.9 & 0.0 & 0.0 & 0.1 \\
\hline g_Acidithiobacillus & 8.5 & 2.6 & 0.0 & 0.0 & 0.0 \\
\hline o__Streptophyta & 2.6 & 2.3 & 0.0 & 0.1 & 0.1 \\
\hline g_L_eptospirillum & 0.8 & 2.2 & 0.0 & 0.1 & 0.0 \\
\hline g_ Thiobacillus & 29.0 & 1.8 & 2.9 & 3.4 & 27.5 \\
\hline g_Bacillus & 0.2 & 1.1 & 2.3 & 2.3 & 1.2 \\
\hline o__Methylophilales & 6.4 & 0.7 & 0.4 & 0.4 & 0.0 \\
\hline f__Rhodospirillaceae & 0.0 & 0.5 & 21.4 & 27.5 & 2.6 \\
\hline f__Bacillaceae & 0.1 & 0.0 & 3.0 & 2.5 & 0.8 \\
\hline g__Mycobacterium & 0.0 & 0.0 & 1.5 & 1.4 & 0.5 \\
\hline o_Rhizobiales & 1.1 & 0.0 & 6.5 & 7.3 & 0.7 \\
\hline f__Sinobacteraceae & 0.9 & 0.0 & 3.8 & 3.3 & 0.6 \\
\hline g__Streptomyces & 0.0 & 0.0 & 8.5 & 3.7 & 0.3 \\
\hline o__koll13 & 0.0 & 0.0 & 7.7 & 8.3 & 1.6 \\
\hline g__Georgenia & 0.0 & 0.0 & 4.2 & 3.0 & 0.4 \\
\hline f__Balneolaceae & 0.0 & 0.0 & 3.5 & 3.6 & 0.2 \\
\hline o__Chromatiales & 0.0 & 0.0 & 2.8 & 1.3 & 0.8 \\
\hline g_Virgibacillus & 0.0 & 0.0 & 2.6 & 2.2 & 0.8 \\
\hline g_Halomonas & 0.0 & 0.0 & 2.3 & 2.4 & 0.5 \\
\hline c_Gemmatimonadetes & 0.0 & 0.0 & 2.3 & 2.1 & 0.4 \\
\hline g__Nocardiopsis & 0.0 & 0.0 & 2.0 & 1.9 & 0.3 \\
\hline g__Actinomadura & 0.0 & 0.0 & 1.8 & 1.2 & 0.3 \\
\hline g__Hyphomicrobium & 0.0 & 0.0 & 1.1 & 1.4 & 0.5 \\
\hline f__Sphingobacteriaceae & 0.0 & 0.0 & 0.0 & 0.0 & 6.0 \\
\hline
\end{tabular}

Figure 3.

Relative abundance (RA) of individual OTUs in replicate grab samples of starting material used for the experiment $\left(t_{0}\right)$. Heat map is normalized within each OTU to the maximum RA (dark red) for that OTU at $t_{0}$. Analysis was limited to OTUs with cumulative $t_{0}$-RA of $>3 \%$. OTU taxonomic identifications are assigned with a minimum similarity of 0.9 at the designated taxonomic level; g_genus; f_family; o_order; and c_class. OTUs highlighted in gold represent known Fe/S-oxidizing organisms as defined in the text. The treatment designations represent grab samples of TO, tailings only (2 replicates), and TC, tailings plus $15 \%$ compost mixture used for tailings plus compost and quailbush treatments (3 replicates). Insufficient sequence reads were obtained from TO- $t_{0}-1$ for analysis. 


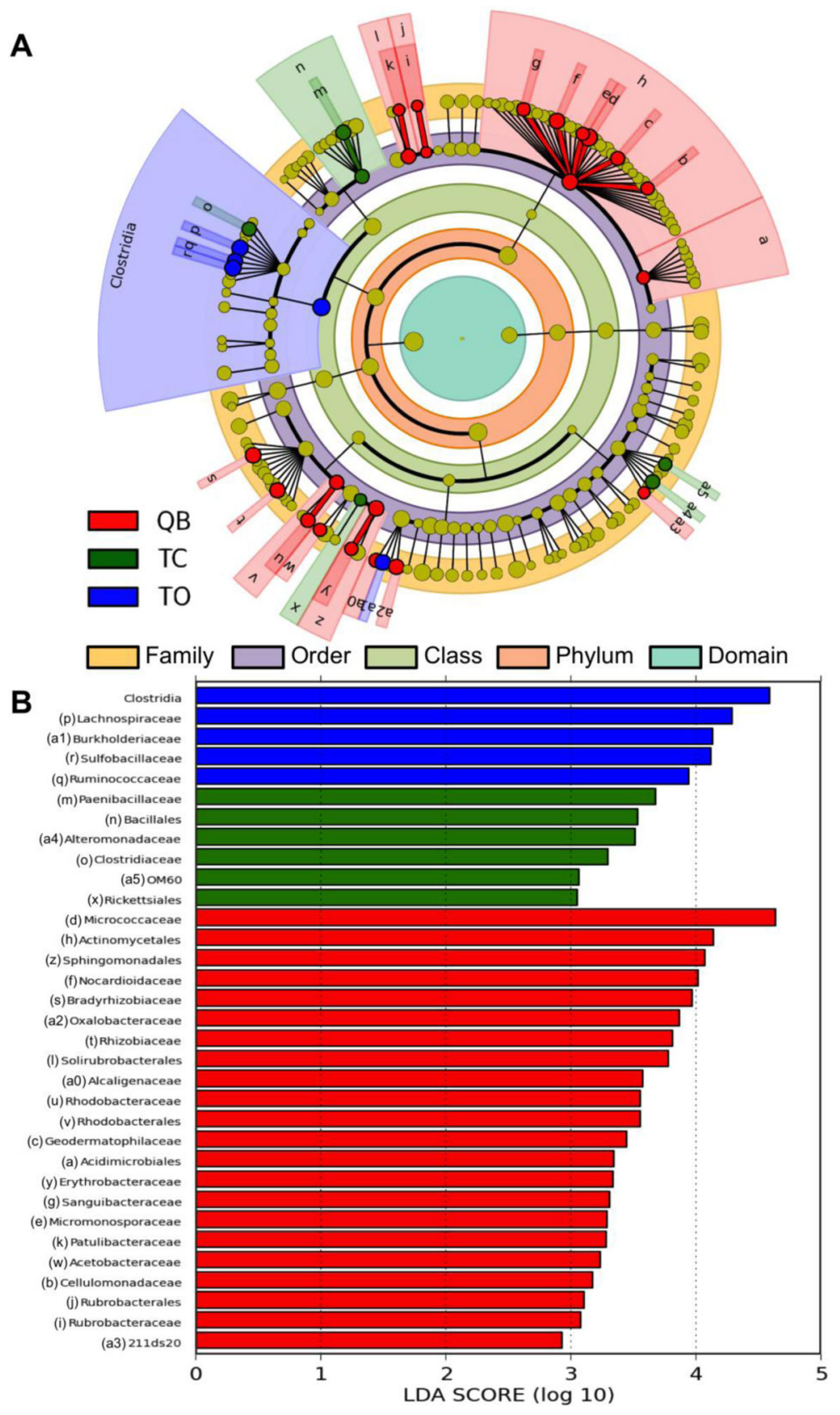

Figure 4.

Cladogram indicating the phylogenetic distribution of microbial lineages associated with the three mesocosm treatments generated using the Linear Discriminant Analysis (LDA) Effect Size (LEfSe) method. The 5 most abundant phyla were analyzed to the family level of taxonomic resolution; lineages with LDA values of 2 or higher as determined by LEfSe are displayed. Differences are represented by treatment color (red indicating QB, green TC, blue TO, and yellow non-significant). Each circle's diameter is proportional to the taxon's abundance. The strategy of multiclass analysis is non-strict (at least one class differential). 
Circles represent taxonomic ranks from domain to family inside to out. Labels are shown of the class, order and family levels. Fig. B shows scores for all the taxa with a LDA score $\geq 2$. 


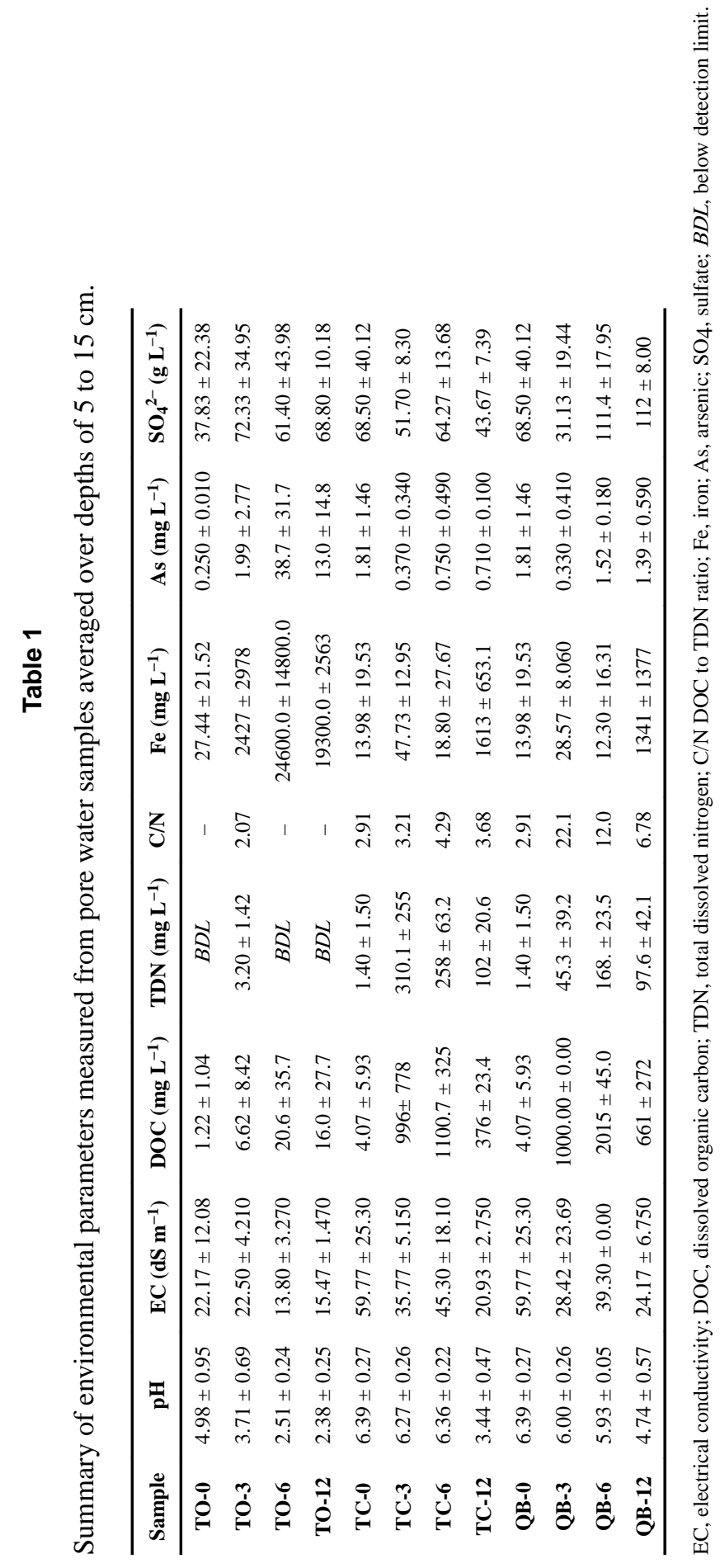




\section{Table 2}

Diversity indexes for iTag data and distribution of OTUs. Values represent means of replicate mesocosms.

\begin{tabular}{|c|c|c|c|c|}
\hline Sample & iTag Reads & Shannon $(H)$ & Simpson $(1-D)$ & OTU Abundance \\
\hline TO- $t_{0}^{\mathrm{b}}$ & 9509 & 2.66 & 0.852 & 127 \\
\hline $\mathrm{TO}-t_{3} \mathrm{~b}$ & 9421 & 2.48 & 0.851 & 109 \\
\hline TO- $t_{6}{ }^{\mathrm{a}}$ & 6125 & 1.45 & 0.594 & 39 \\
\hline TO- $t_{12}{ }^{\mathrm{b}}$ & 9057 & 2.94 & 0.861 & 298 \\
\hline $\mathrm{TC}-t_{0}^{\mathrm{c}}$ & 14286 & 3.85 & 0.918 & 534 \\
\hline $\mathrm{TC}-t_{3} \mathrm{~b}$ & 14959 & 3.61 & 0.836 & 579 \\
\hline $\mathrm{TC}-t_{6}^{\mathrm{c}}$ & 27257 & 3.54 & 0.882 & 642 \\
\hline $\mathrm{TC}-t_{12}{ }^{\mathrm{b}}$ & 12062 & 3.04 & 0.852 & 300 \\
\hline $\mathrm{QB}-t_{0}^{\mathrm{c}}$ & 14286 & 3.85 & 0.918 & 534 \\
\hline $\mathrm{QB}-t_{3}{ }^{\mathrm{b}}$ & 14776 & 3.87 & 0.905 & 586 \\
\hline $\mathrm{QB}-t_{6}^{\mathrm{b}}$ & 16030 & 4.17 & 0.930 & 642 \\
\hline $\mathrm{QB}-t_{12}{ }^{\mathrm{b}}$ & 14561 & 4.18 & 0.927 & 608 \\
\hline
\end{tabular}

OTU, operational taxonomic unit (97\% identity cut-off value)

$t_{0}, t_{3}, t_{6}, t_{12}$, designate sampling time points of $0,3,6$, and 12 months

Quality sequence reads were not obtained from all mesocosms at every time point. Superscripts indicate the number of mesocosms represented at each time point: $\mathrm{a}=1, \mathrm{~b}=2$, or $\mathrm{c}=3$. 


\section{Table 3}

Nonparametric analysis of similarity (ANOSIM) of the microbial community taxonomic composition based on Bray-Curtis pairwise dissimilarity matrices

\begin{tabular}{ccc}
\hline \multirow{2}{*}{ Treatments } & \multicolumn{2}{c}{ One-Way ANOSIM } \\
& $\boldsymbol{R}$ & $\boldsymbol{P}$ \\
\hline TO - TC & 0.1784 & $\mathbf{0 . 0 4 7 6}$ \\
TO - QB & 0.3295 & $\mathbf{0 . 0 1 9 3}$ \\
TC - QB & 0.0361 & 0.2898 \\
\hline
\end{tabular}




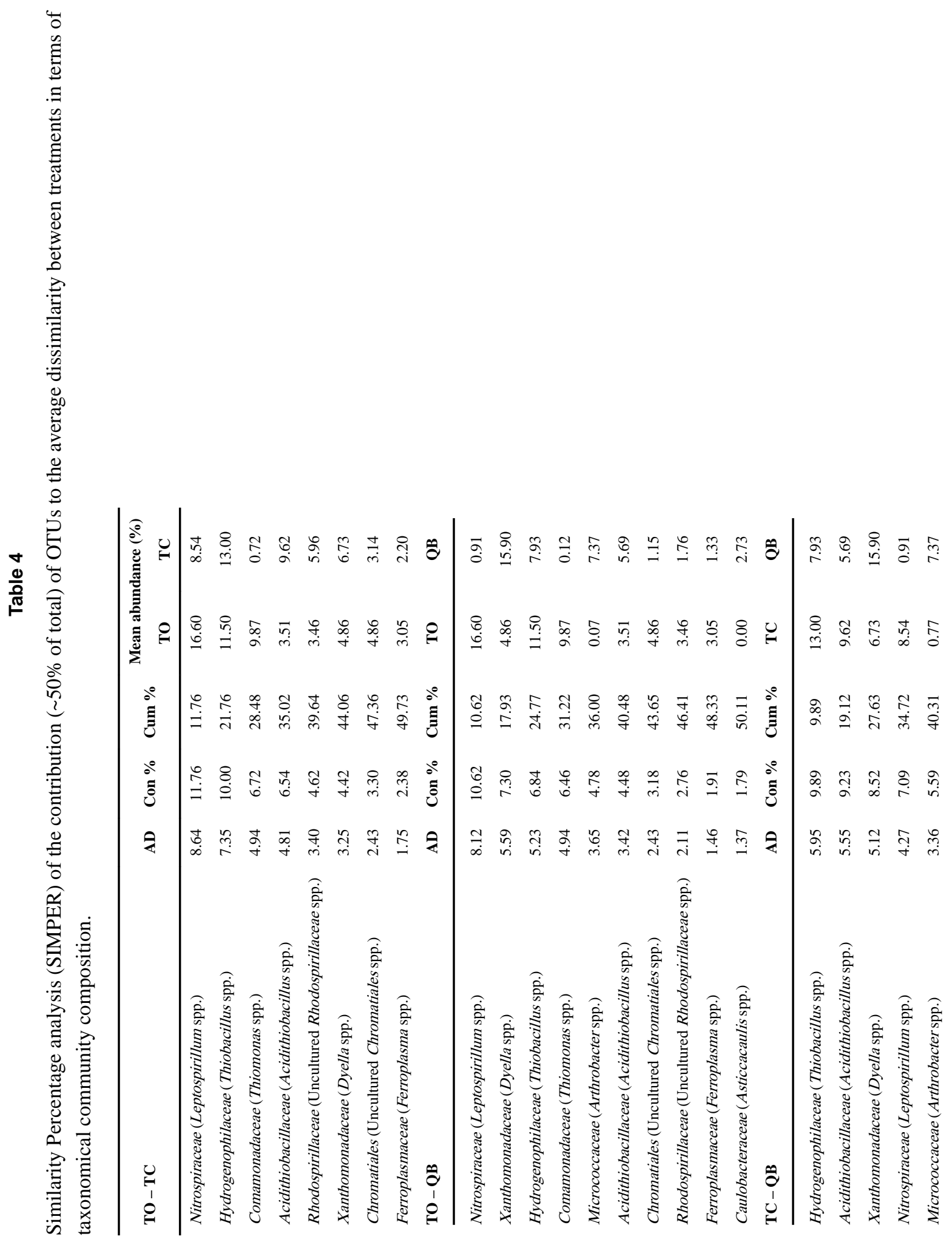


Valentín-Vargas et al.

Page 31

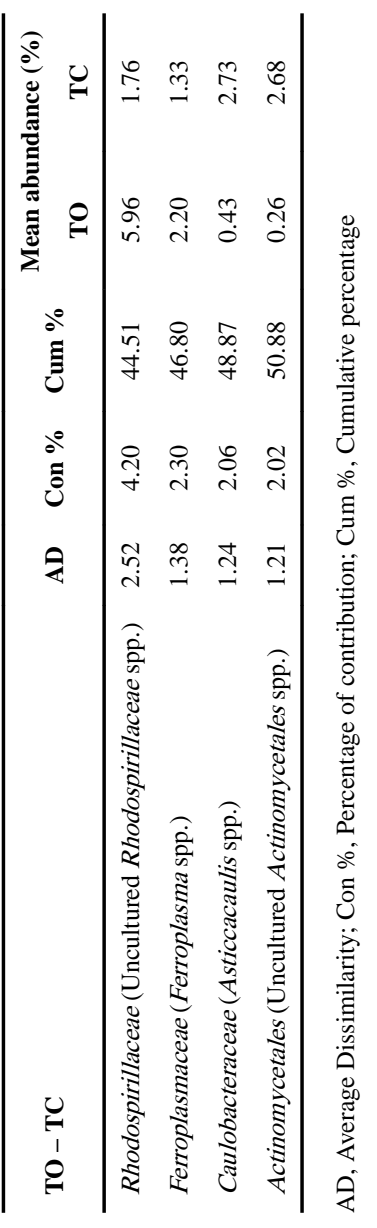

